\title{
Objective analysis of typographies by image processing based on the optotypes' guidelines
}

\section{Análisis objetivo de tipografías por procesado de imagen basado en las convenciones de los optotipos}

\author{
Héctor C. Abril, Montserrat Tàpias $\left.{ }^{*}\right)$, Aurora Torrents \\ Departament d'Òptica i Optometria. Universitat Politècnica de Catalunya, Spain. \\ (*) Email: mtapias@oo.upc.edu \\ Recibido / Received: 21/11/2012. Revisado / Revised: 11/02/2013. Aceptado / Accepted: 12/02/2013. \\ DOI: http://dx.doi.org/10.7149/OPA.46.1.73
}

\begin{abstract}
:
Most near vision reading charts include the visual acuity values. On the one hand, most reading charts are constructed using the Times New Roman typography. On the other hand, visual acuity is commonly measured with optotypes not with typographies. In this paper, an objective analysis by image processing of the stroke width of some typographies (Times New Roman, Arial, Arial Bold, Sloan and Optotipica), suitable to be used in acuity and near vision reading charts, is performed. Taking the tumbling E as the optotype model, two new parameters are defined for each typography compared with that: the degree of similarity to an optotype, $D S O$, and the spread, $S_{p}$. $D S O$ accounts for the similarity of the character to an optotype, whilst $S_{p}$ accounts for the variability of the stroke width all over the character. The parameters defined show that none of the conventional typographies analyzed is suitable to be considered as an optotype, being Times New Roman the less similar and Arial Bold the most. In this sense, the equivalent visual acuity values of typographies used as optotypes are not univocally determined. Thus, a reflection is needed: do reading charts have to include visual acuity values? And, which is the stroke width needed to compute them?
\end{abstract}

Key words: Near Vision Reading Charts, Visual Acuity, Typography, Image Processing.

\section{RESUMEN:}

La mayoría de las cartas de lectura incorporan valores de agudeza visual. Por una parte, la mayoría de estas cartas están diseñadas usando la tipografía Times New Roman. Por otra parte, la agudeza visual se mide habitualmente con optotipos, no con tipografías. En este trabajo se ha realizado un análisis objetivo, mediante procesado de imágenes, del grosor del trazo de algunas tipografías (Times New Roman, Arial, Arial Bold, Sloan y Optotipica) susceptibles de ser usadas en cartas de lectura y cartas de agudeza visual de cerca. Tomando como optotipo modelo la E de Snellen, se han definido dos nuevos parámetros para cada tipografía que permiten compararla con aquélla: el grado de similitud a un optotipo, $D S O$, y la dispersión, $S_{p}$. $D S O$ evalúa la similitud de un carácter a un optotipo, mientras que $S_{p}$ refleja la variabilidad de la anchura del trazo a lo largo del carácter. Los parámetros definidos muestran que ninguna de las tipografías convencionales analizadas es adecuada para ser considerada como un optotipo, siendo Times New Roman la menos similar y Arial Bold la más similar a un optotipo. En este sentido, el valor de la agudeza visual equivalente de las tipografías usadas como optotipos no está determinado de forma unívoca. Así pues, se hace necesaria una reflexión: las cartas de lectura, ¿tienen que incorporar los valores de agudeza visual? Y, ¿cuál sería el grosor de trazo requerido para calcular tales agudezas?

Palabras clave: Cartas de Lectura, Agudeza Visual, Tipografía, Procesado de Imágenes. 


\section{REFERENCIAS Y ENLACES / REFERENCES AND LINKS}

[1]. R. B. Rabbetts, Bennett \& Rabbetts' Clinical Visual Optics, $4^{\text {th }}$ Edt., Butterworth-Heinemann, Edinburgh, UK (2007).

[2] ICO, "Visual acuity measurement standard", International Council of Ophthalmology, Visual Functions Committee, Italian J. Opthalmol. II/I, 1-15 (1988).

[3]. UNE-EN ISO 8596:2009, “Óptica oftálmica. Ensayo de la agudeza visual. Optotipos normalizados y su presentación" (2009).

[4]. L. L. Sloan, "New test charts for the measurement of visual acuity at far and near distances", Am. J. Ophthalmol. 48, 807-813 (1959).

[5]. NAS-NRC, "Recommended standard procedures for the clinical measurement and specification of visual acuity", Report of working group 39. Commitee on Vision. Assembly of Behavioural and Social Sciences, National Research Council, National Academy of Sciences, Advances in Opthalmology 41, 103-148 (1980).

[6]. BS 4274-1, "Visual acuity test types. Specification for test charts for clinically determining distance visual acuity", British Standards Institute (2003).

[7]. D. G. Pelli, J. G. Robson, A. J. Wilkins, "The design of a new letter chart for measuring contrast sensitivity", Clinical Vision Sci. 2, 187-199 (1988).

[8]. D. B. Elliott, D. Whitaker, L. Bonette, "Differences in the legibility of letters at contrast threshold using the Pelli-Robson chart", Ophthal. Physl. Opt. 10, 323-326 (1990). DOI

[9]. I. L. Bailey, J. E. Lovie, "New design principles for visual acuity letter charts", Am. J. Optom. Physl. Opt. 53, 740-745. (1976). DOI

[10]. A. H. Tunnacliffe, Introduction to Visual Optics, $4^{\text {th }}$ Edt., The Association of British Dispensing Opticians, Godmersham, UK (1993).

[11]. M. L. Bernard, B. S. Chaparro, M. M. Mills, C. G. Halcom, "Comparing the effects of text size and format on the readability of computer-displayed Times New Roman and Arial text", Int. J. Hum.-Comput. St. 59, 823-835 (2003).

[12]. A. Arditi, J. Cho, "Serifs and font legibility", Vision Res. 45, 2926-2933 (2005). DOI

[13]. A. Arditi, J. Cho, "Letter case and text legibility in normal and low vision", Vision Res. 47, 2499-2505 (2007). DOI

[14]. $\quad$ http://psych.nyu.edu/pelli/software.html (Last visited: 2013/01/11).

[15]. http://www.imagemagick.org/script/index.php (Last visited: 2013/01/11).

[16]. E. R. Dougherty, An Introduction to Morphological Image Processing, SPIE Optical Engineering Press, Bellingham, USA (1992).

[17]. M. Tàpias, H. Abril, A. Torrents, "Suitability of conventional typographies to measure visual acuity", Abstracts of the Annual Conference of the European Academy of Optometry and Optics (2012).

[18].http://ocw.upc.edu/curs/20352/Altres.

\section{Introduction}

Visual acuity, described as the smallest angular size of detail that can be resolved by an observer, is usually assessed by determining the smallest symbols, letters or words that can be identified correctly. Such symbols or observation targets are known as optotypes.

Optotype design is mainly based on the Landolt ring and the tumbling E tests [1-3] (Fig. 1 ), in which the critical detail, $s$, to be resolved is one-fifth of the optotype height, $5 s$. Therefore, letter optotypes are commonly non serif uppercase letters constructed on a five-by-five $(5 s \times 5 s)$ or five-by-four $(5 s \times 4 s)$ grid pattern, with the stroke width $s$ of the letter measuring one-fifth of the total optotype height $5 s$. Such a $5 s \times 5 s$ optotype was designed by Sloan [4], and was adopted by the NAS-NRC Committee on Vision (1980) [5] as the standard for visual acuity testing in the USA and, with some modifications, also by the British Standard (2003) on optotypes [6]. These Sloan optotypes consist of ten sansserif uppercase letters (built on a $5 s \times 5 s$ grid) 


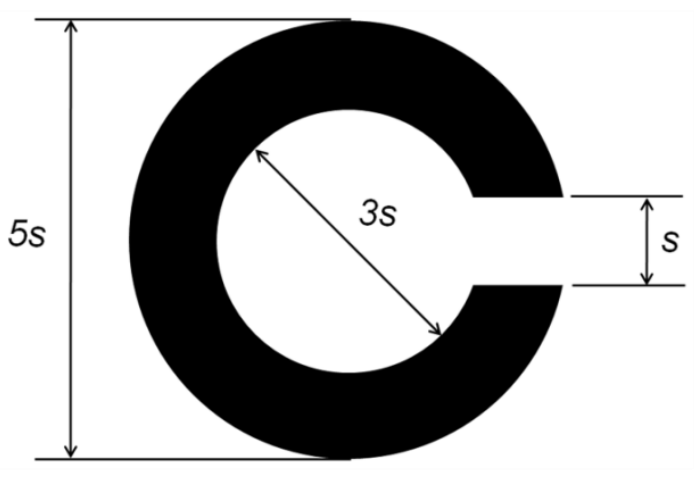

(a)

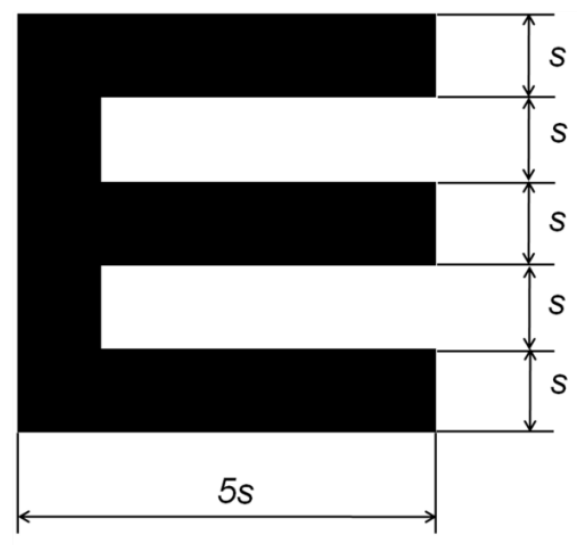

(b)

Fig. 1: Landolt ring (a) and tumbling E (b) tests.

-CDHKNORSVZ- of similar, although not identical, legibility, and has been used to design both high-contrast acuity charts, like the Ferris chart, and charts with various degrees of contrast, such as the Pelli-Robson chart, for the evaluation of contrast sensitivity $[7,8]$. On the other hand, $5 s \times 4 s$ ten non serif letter optotypes were adopted by the British Standard [6] -DEFHNPRUV - and used, for instance, in the Bailey-Lovie visual acuity chart [9].

Many practitioners and companies design their own visual acuity reading charts using typographies contained in word processors. Thus, the goal of this work is to analyze objectively the similarity between some typographies suitable to be used in the construction of visual acuity or reading charts and the optotypes. Our method is based on image processing techniques, taking into account optotype design criteria.

\section{Methods}

\section{2.a. Typographies selected}

Following the recommendations of the National Academy of Sciences [5] on tests of ability to read continuous text, "the test material should be representative of the patients reading needs. It could include samples of ordinary books, magazines and newspapers and of more difficult material such typed letters", most reading charts such as MNRead or Bailey-Lovie and the Mallett near vision unit contain texts or series of words typed in Times New Roman. Such typestyle, was first used in the London Times newspaper, in 1932 [10]. Times New Roman and Arial are typically included in office software suites and used as the default typefaces. Moreover, both typestyles are the subject of several modern studies on readability [11-13] for normal and/or low vision and adopted for many companies in the construction of their near acuity charts for commercial or advertising purposes. Therefore, these typographies were included in our work in addition to Arial bold.

Several authors have attempted to design computer fonts based on the described five-byfive ideal Landolt ring or tumbling $\mathrm{E}$ proportions, in order to allow the construction of words and sentences using all letters of the alphabet. An example of such a computer font, called Sloan, was created by Pelli [14] and is freely available for research purposes. Pelli took the ten original Sloan letters and, on the same bases, completed the rest of the upper-case alphabet. Only upper-case letters are available with this typography. This is the fourth typography style analyzed in this study.

\section{2.b. Type image generation}

The images for each type were generated taking into account the tumbling E optotype, with size $5 s^{*} 5 s$ (width $*$ height). The software used for image generation was ImageMagick [15]. In this work we set $s=15$ pixels, and took the upper case $\mathrm{E}$ as reference for the selection of the corresponding type font size; i.e. we search a font size for each type such that its upper case E has a size of exactly 75 pixels. The same font size was used to generate all types (upper and lower cases and numbers), except the Sloan font that 


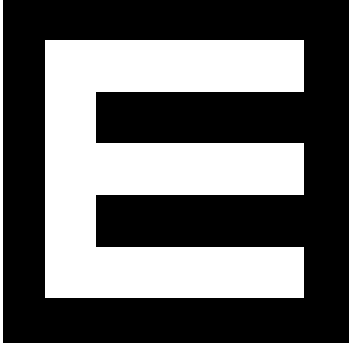

(a)

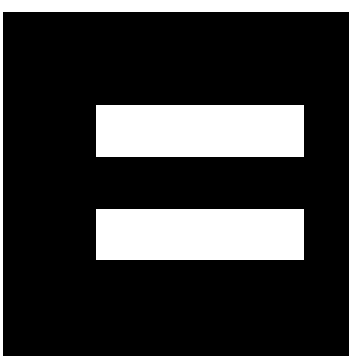

(c)

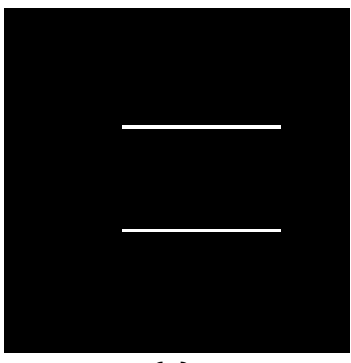

(e)

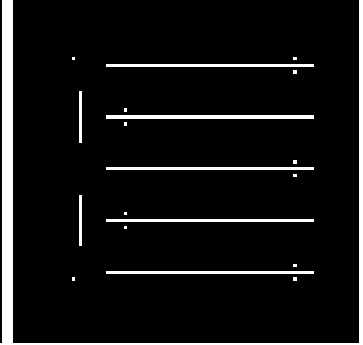

(b)

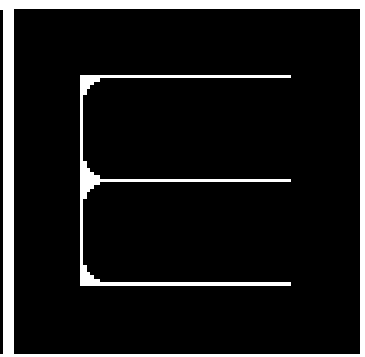

(d)

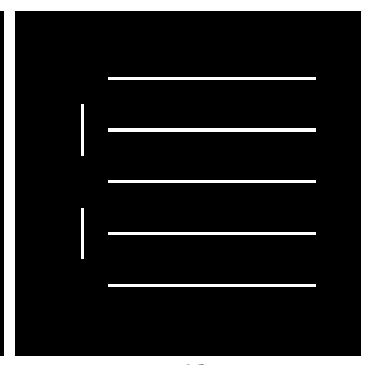

(f)
Fig. 2. a) Tumbling E image $\left(I_{0}\right)$, b) $B C$ applied to image $I_{0}\left(I_{f}\right)$, c) negative Io image only within the bounding box of $I_{0}\left(I_{N}\right)$, d) morphological erosion of $I_{0}$, e) morphological erosion of $I_{N}$, and f) the image obtained by selecting the objects in $I_{f}$ that match some pixel with the objects in d) and e).

only has upper case characters. One binary image, $I_{0}$, was generated for each type including a margin of 20 (Fig. 2a).

\section{2.c. Binary correlation}

The aim of correlation is to quantify the zones of the image with $d$ thickness and spacing. With this objective we designed a binary correlation $(B C)$ and applied some morphological operations to each type image. The whole process and the analysis of the results are described below.

First, the $B C$ is defined as the following function:

$$
I_{f}=B C\left(I_{0}, d\right)
$$

where $I_{0}$ is the original type image (Fig. 2(a)) and $d$ is the diameter of the circular area evaluated around each pixel in $I_{0}$. The result $I_{f}$ is a binary image, function of $d\left(I_{f}(d)\right)$. Every pixel in $I_{f}(d)$ is 1 if at least a couple of pixels exist with the same value ( 0 or 1 ) lying on diametrically opposed positions with diameter $d$, that are also connected through a line of pixels with the opposite corresponding value ( 1 or 0$)$. In any other case, every pixel in $I_{f}(d)$ is 0 . This can be observed in Fig. 2, in which we obtain the result shown in Fig. 2(b), with parameter $d=15$, for the Fig. 2(a).

Second, notice that $I_{f}(d)$ represents lines corresponding to thickness and spacing regions. However, there are also some misclassified pixels as shown in Fig. 2(b). Therefore, we need to filter this image. We carry this out using two images obtained from morphological erosion and combine the images with a logical "OR" according to the following equation:

$$
I_{m}(d)=\left\{\begin{array}{l}
\left(I_{0}-E(d)\right) \\
\text { or } \\
\left(I_{N}-E(d)\right)
\end{array},\right.
$$

where $I_{0}$ is the original type image (Fig. 2a), $I_{N}$ is the negative $I_{0}$ image only within the bounding box of the type (Fig. 2(c)), and $E(d)$ is a circular structural element of diameter $d$ for the morphological erosion [16]. Figures 2(d) and 2(e) show the results from the morphological erosion from $I_{0}$ and $I_{N}$, respectively.

Finally, the resulting image $I_{o t}(d)$ is obtained by selecting the objects in $I_{f}(d)$ that match some pixel with the objects in $I_{m}(d)$ (Fig. 2(f)).

\section{2.d. Degree of similarity to an optotype and spread measures}

For every character we define the $O_{f}$ optotypical function as:

$$
O_{f}(d)=\sum I_{o t}(d)
$$

where $d$ is the inner diameter of the ring considered. $O_{f}$ is the frequential distribution of the stroke widths and spacings contained in the character. In order to be more generalist, we use $O_{f}\left(s_{n}\right)$ where $s_{n}$ is the diameter $d$ normalized by $s$ (one fifth of the height), $s_{n}=d / s$ and $0<s_{n}<2$. In our case $s=15$ pixels. Figure 3 shows the results of the $O_{f}$ function after applied to the tumbling E (Fig. 2(a)). As we can see in Fig. 3, there is only one contribution to the optotypical function: 
$s_{n}=1$. For the rest of values of $s_{n}, O_{f}\left(s_{n}\right)=0$. Any other optotype different from the tumbling $E$ has the previous optotypical function.

For similarity with the tumbling E optotype, it is interesting to analyze the optotypical function of the upper case letter $\mathrm{E}$ in Arial and Times New Roman typographies. Figures 4(a) and 4(c) show the images of the two letters. Figures 4(b) and 4(d) display their corresponding $O_{f}$ function. On the one hand, Arial E optotypical function has a low spread, which is important, but it shows their two predominant stroke widths out of $s_{n}=1$ units. On the other hand, Times New Roman Optotypical function shows much higher spread with no one peak at $s_{n}=1$, what makes this E completely unsuitable to be used as an optotype. The comparison of Figs. 4(b) and 4(d) with Fig. 3 illustrates the previous idea.

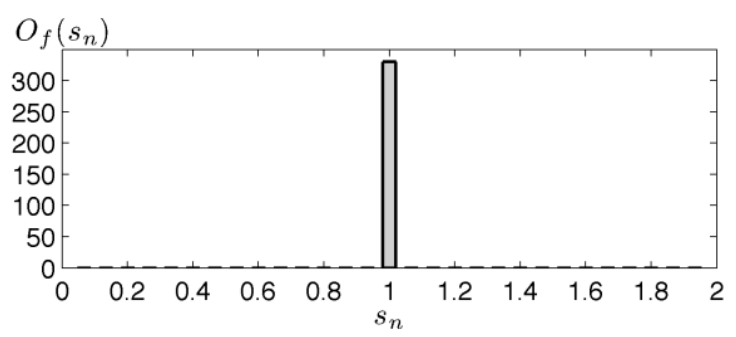

Fig. 3. $O_{f}\left(s_{n}\right)$ function for image E.
From the optotypical function, two parameters are defined to measure the suitability of a character to be used as an optotype: the Degree of Similarity to an Optotype $(D S O)$ and the Spread $\left(S_{p}\right)$.

DSO indicates the predominance of the stroke width and spacing $s_{n}=1$ overall the character,

$$
D S O=\frac{O_{f}(1)}{\sum O_{f}\left(s_{n}\right)}, 0<s_{n}<2,
$$

where $0<D S O \leq 1$. The latter is computed as the value of the optotypical function in $s_{n}=1$ divided by the summation of all the $s_{n}$ contributions. As a true optotype has only optotypical function $\neq 0$ in $s_{n}=1$, it is obvious that its $D S O=1$. The more close to 1 is the $D S O$ of a character, the more similar to an optotype is.

Spread $\left(S_{p}\right)$ accounts for the dispersion of stroke widths contained in the character:

$$
S_{p}=\sqrt{\frac{\sum\left(o_{f}\left(s_{n}\right) \cdot\left(s_{n}-1\right)^{2}\right)}{\sum o_{f}\left(s_{n}\right)}}, 0<s_{n}<2,
$$

where $0<S_{p}<\infty$. A true optotype has null spread. This parameter helps us to choice among characters that have the same DSO in the sense that the one with lower spread is the most similar to an optotype.

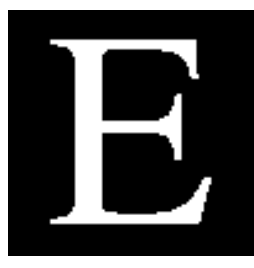

(a)

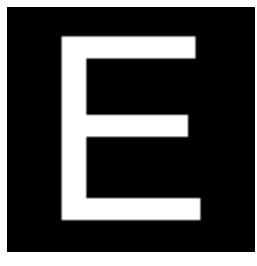

(c)

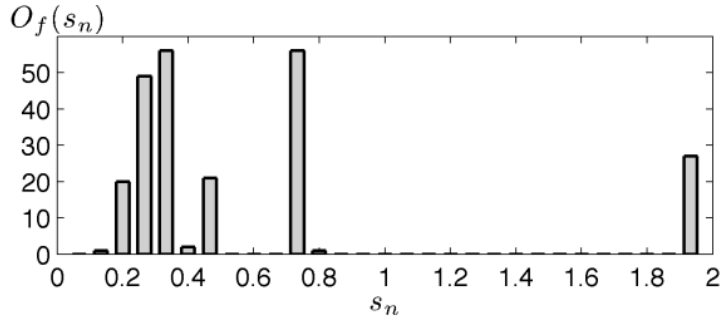

(b)

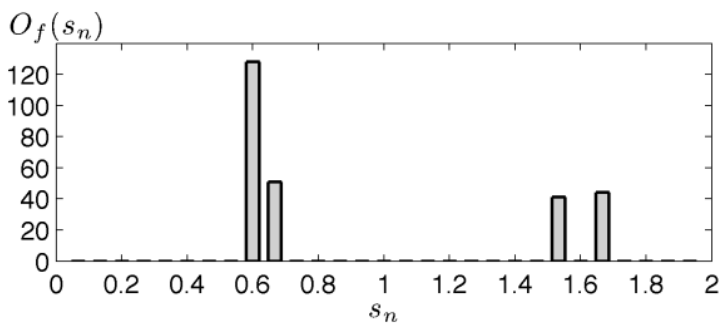

(d)

Fig. 4. a) E Times, b) $O_{f}$ of E Times New Roman, c) E Arial and d) $O_{f}$ of E Arial. 
As these two parameters can be computed for each character, a DSO and $S_{p}$ average characterizes each typography, what helps us to know which one is more suitable to be used as optotype.

\section{Results and discussion}

Following the previous section, an $O_{f}\left(s_{n}\right)$ function was obtained for each character in the typographies analyzed. Recall that the strokewidth of an optotype is one-fifth of the total height therefore, there is only contribution to the $O_{f}\left(s_{n}\right)$ function by $s_{n}=1$. Figure 5(a), from top to bottom, shows Times New Roman upper case, lower case and numerals $O_{f}\left(s_{n}\right)$ function. Black values are the highest and white, the lowest. It can be seen that $O_{f}(1)=0$ in almost all the characters and an important spread is observed. Figure 5(b) shows $O_{f}\left(s_{n}\right)$ functions for Arial in the same sequence as the aforementioned typography. Despite $O_{f}(1)=0$ in almost all the characters, a generalized low spread of $O_{f}\left(s_{n}\right)$ functions is shown, what makes Arial more similar to an optotype than Times New Roman, in the sense that its variability is very low. Arial bold's $O_{f}\left(s_{n}\right)$ functions can be seen in Fig. 5(c). Although in this case all $O_{f}(1)>>0$, note that its $S_{p}$ is not insignificant, therefore it disables its use as a true optotype. Figure 5(d) displays $O_{f}\left(s_{n}\right)$ functions of the only alphabet, upper case, belonging to the Sloan typography, showing similar $O_{f}$ as a true optotype.

With the goal of allowing for the construction of reading charts and to follow the design philosophy of optotypes, we created the font Optotipica [17], which is a True Type font suitable for any software system supporting Open Type fonts. It contains the Latin Basic encoding with lining figures and all the diacritics used in Western Europe. It includes upper and lower-case letters and numerals (Fig. 6), thus allowing for the construction of any type of near vision reading chart, as well as distance visual acuity testing letter charts. Upper-case letters are contained in a $5 s \times 4 s$ grid pattern with a stroke-width $s$. The em square dimensions are $3 \mathrm{~s} \times 3 \mathrm{~s}$ except in letters $\mathrm{f}, \mathrm{i}, \mathrm{j}, \mathrm{l}, \mathrm{m}, \mathrm{t}$ and $\mathrm{w}$. The dimensions of ascenders and descenders are $2 s$. Numbers are contained in the same grid as upper case except 1 and 0 . A first version of our font can be obtained at [18] and used without permission for research purposes. As can be seen in Fig. 7, Optotipica is the only full typography that accomplishes both requirements: almost all $O_{f}\left(s_{n}\right)$ functions have a maximum at $O_{f}(1)$ and their degree of spread tends to zero. From the point of view of a reading chart intending to give visual acuity values as an acuity chart, a typography such as Optotipica fulfills the requirements of optotypes despite the fact that its readability could not be as high as Times New Roman or Arial's. It is worth mentioning that our aim in creating Optotipica was solely to give an example of a typography that combines accurate measurements of visual acuity and readability at the same time.

Figure 8 displays the DSO of upper case, lower case and numerals of the typographies considered. In this plot, one can see the DSO of every single character of the five typographies considered, and sets a visual comparison among them. Optotipica and Sloan are reaching the upper position of the graph, matching perfectly in the upper case characters (the only ones that Sloan has). There is another match also but at the bottom of the graph, between Times New Roman and Arial: both typographies have zero DSO. This graph is helpful in the moment to select a typography to design a reading chart suitable to measure visual acuity or, simply a letter acuity chart. It lets to know the DSO of every single character, offering the optometrist the opportunity to use the most appropriate characters to achieve a known DSO. In this sense, one can objectively decide the use of the chart: or lecture chart or single letter acuity chart. Referring to upper case, Optotipica and Sloan show the highest values $(0.73$ and 0.74 respectively) while Arial and Times New Roman have 0 DSO. Arial bold's DSO is half way between the first group and the second group (0.42). Optotipica shows in lower case and numerals the highest and identical values of DSO (0.77). It is followed by Arial bold ( 0.37 and 0.36 ) and is 0 for Times New Roman and Arial (Table I(a)).

Figure 9 depicts the spread of upper case, lower case and numerals of the typographies 


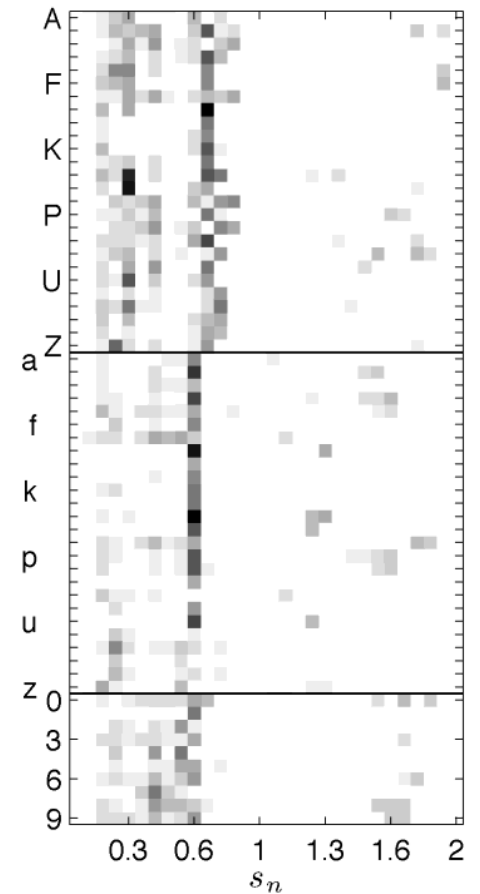

(a)

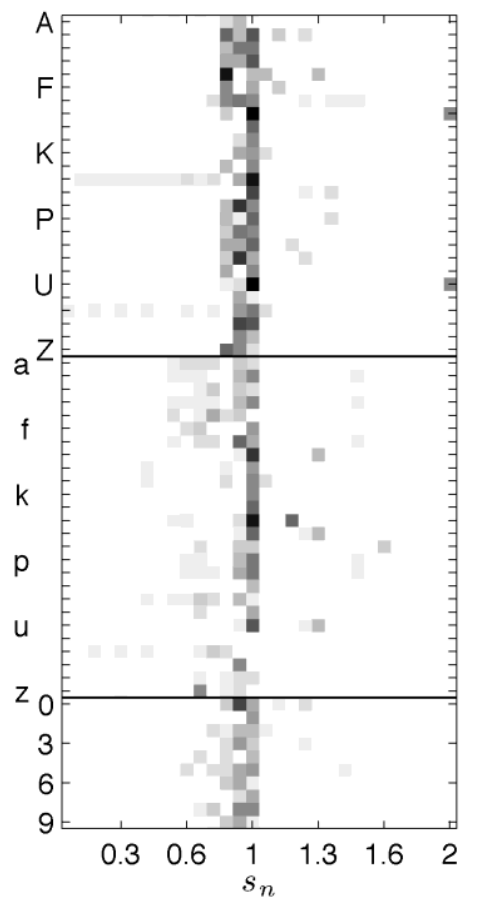

(c)
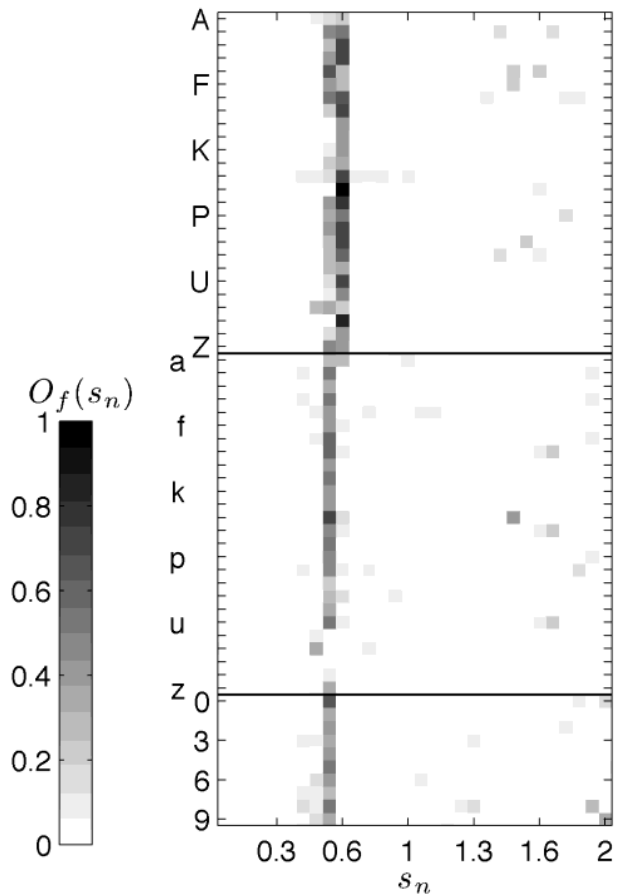

(b)
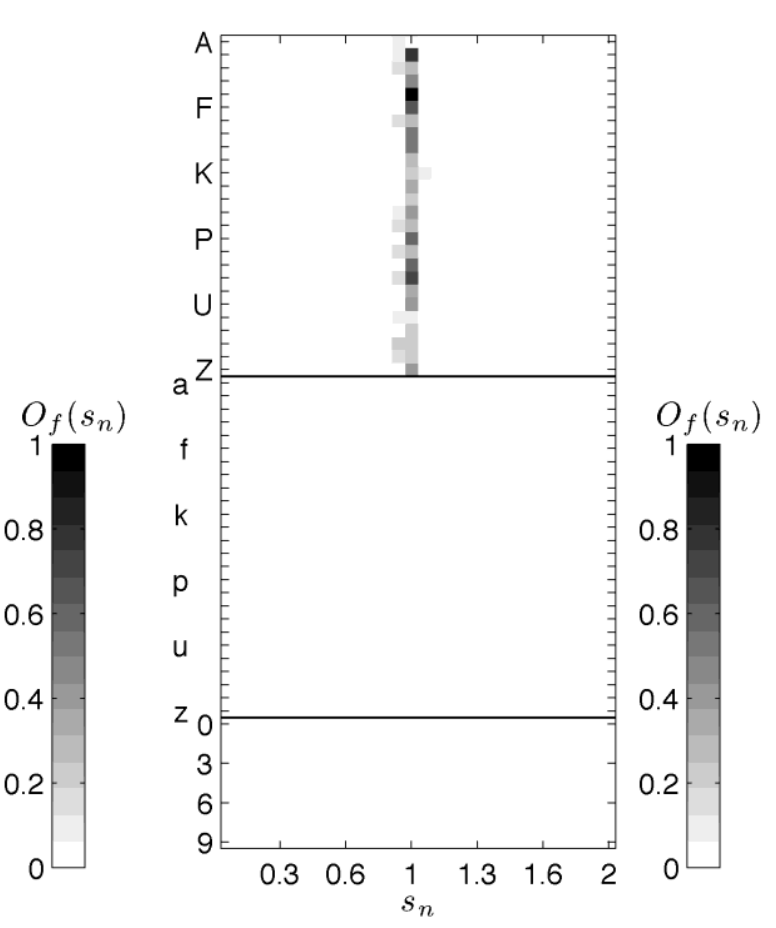

(d)

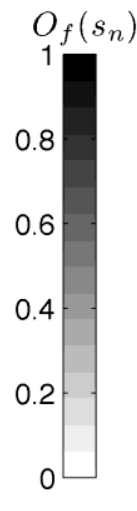

Fig. 5. Normalized optotypical functions, $O_{f}$ of a) Times, b) Arial, c) Arial Bold and d) Sloan. 


\section{ABCDEFGHIJKLMN OPORSTUVWXYZ}

\section{abcdefghijklmn opqrstuvwxyz 1234567890}

Fig. 6. Optotipica typography.

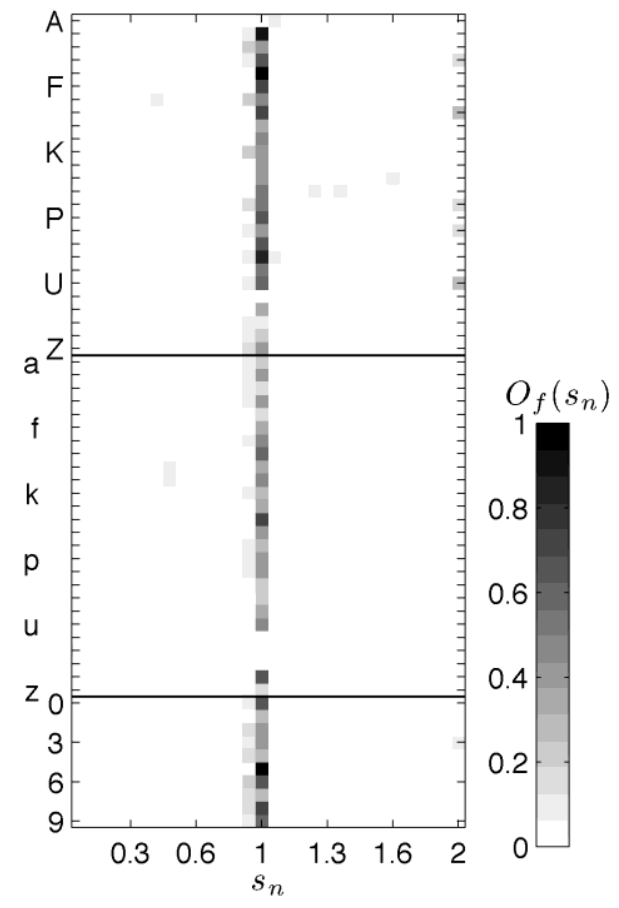

Fig. 7. Normalized optotypical functions, $O_{f}\left(s_{n}\right)$, of Optotipica typography. considered. This refines the information of the plot of Fig. 8 and gives a visual help when deciding among two typographies scoring the same $D S O$ in the design of a chart. The lower spread of a character, the more stroke width uniformity all over its extension, and more suitable to measure visual acuity is. In relation to upper case, Sloan, Optotipica and Arial bold have the lowest $S_{p}$, being $0.11,0.14$ and 0.16 respectively. They are followed by Arial (0.39), and Times New Roman (0.52). In lower case, the lowest $S_{p}$ is shown by Optotipica (0.13), followed by Arial bold (0.25), Arial (0.45) and Times New Roman (0.52). $S_{p}$ in numerals has the same tendency as in lower case, with values alike, except in Arial bold (0.16) (Table I(b)).

From the mean values per typography of $D S O$ and $S_{p}$ listed in Table I, it is noticeable that for upper case characters, Sloan and Optotipica are the more similar to a true optotype, in the sense that they have the highest and coincident DSO value (0.7) and the lowest spread $S_{p}$ (0.1). Moreover, Optotipica, including lower case and numerals, fulfills the task to perform visual acuity measures with reading charts. 


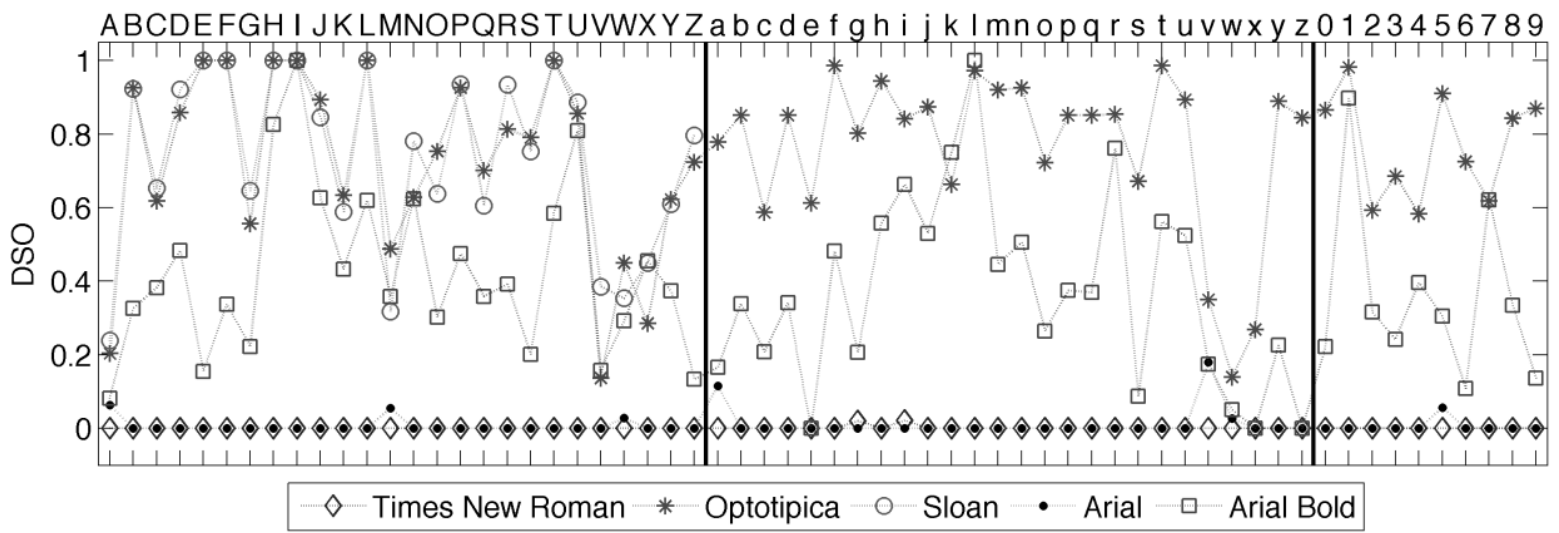

Fig. 8. Degree of Similarity to an Optotype of the considered typographies.

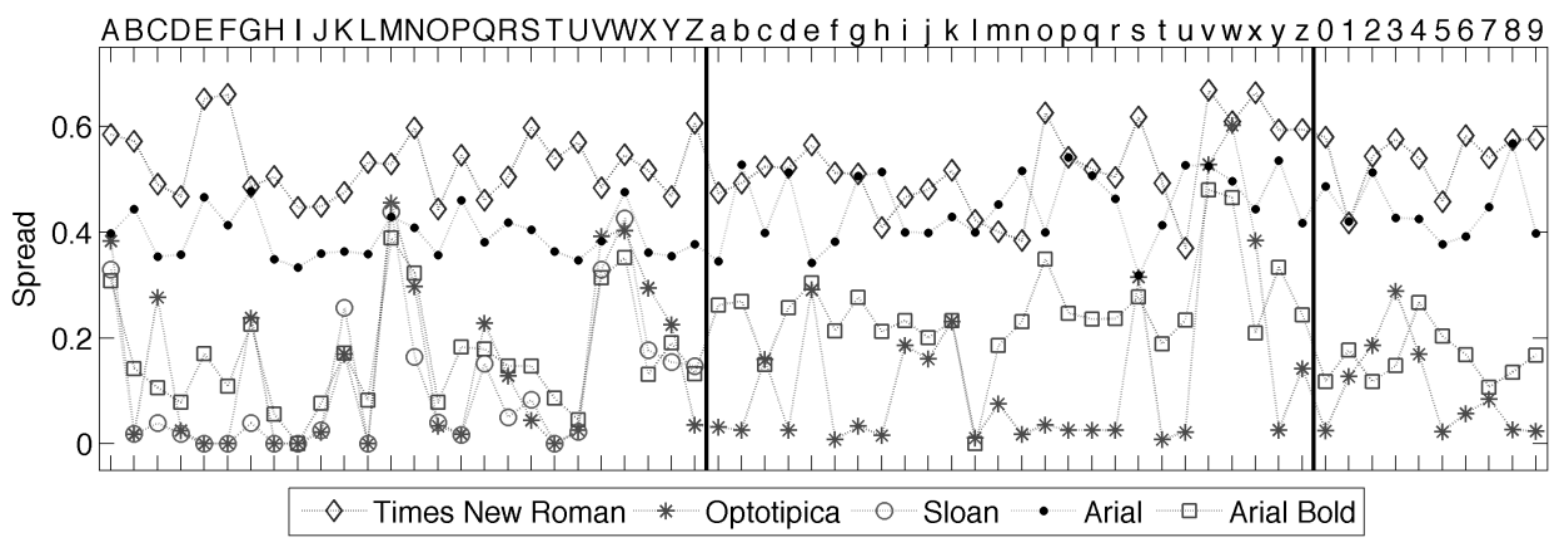

Fig. 9. Spread of the considered typographies.

Table I.

(a) DSO and (b) Spread of the typographies considered.

DSO

\begin{tabular}{cccccc} 
& Times New Roman & Optotipica & Sloan & Arial & Arial Bold \\
\hline Upper case & 0.00 & 0.73 & 0.74 & 0.01 & 0.42 \\
Lower case & 0.00 & 0.77 & - & 0.01 & 0.37 \\
Numerals & 0.00 & 0.77 & - & 0.01 & 0.36 \\
mean typo. & $\mathbf{0 . 0 0}$ & $\mathbf{0 . 7 5}$ & $\mathbf{0 . 7 4}$ & $\mathbf{0 . 0 1}$ & $\mathbf{0 . 3 8}$ \\
\hline
\end{tabular}

(a)

\section{Spread}

\begin{tabular}{cccccc} 
& Times New Roman & Optotipica & Sloan & Arial & Arial Bold \\
\hline Upper case & 0.53 & 0.14 & 0.11 & 0.39 & 0.16 \\
Lower case & 0.52 & 0.13 & - & 0.45 & 0.25 \\
Numerals & 0.54 & 0.10 & - & 0.45 & 0.16 \\
mean typo. & $\mathbf{0 . 5 3}$ & $\mathbf{0 . 1 2}$ & $\mathbf{0 . 1 1}$ & $\mathbf{0 . 4 3}$ & $\mathbf{0 . 1 9}$ \\
\hline
\end{tabular}

(b) 


\section{Conclusions}

An objective evaluation by image processing of the stroke width and spacings of typographies shows that not all of them are suitable to be considered as a true optotype. Anyway, it is not surprising that Times New Roman is the typography the less similar to an optotype; a simple visual inspection of its structure leads to this conclusion in a qualitative way. Quantitatively, it has $D S O=0$ and the highest spread of the typographies analyzed. Moreover, it is included in several gold standard reading charts (Bailey-Lovie, Lighthouse and MNRead) that provide a visual acuity label that is not univocally defined from our point of view. We think that there are other standard typographies such as Arial bold or Arial that may better accomplish the aforementioned mission than Times New Roman. Therefore, a first reflection on the design of reading charts is needed: Do
Times New Roman reading charts have to include visual acuity values? A second reflection is about the need for a method to standardize the typographies used in the assessment of visual acuity with reading charts. In this sense, the method that we have proposed in this paper gives an objective and analytical method to classify typographies following the guidelines of optotypes.

\section{Acknowledgements}

We thank Andreu Balius for his technical support in the creation of Optotipica and Miquel Ralló, José Luis Alvarez and Genís Cardona for their advice. This work was supported by the Ministerio de Ciencia e Innovación (Projects DPI2009-08879 and PSI2009-11062). 